\title{
Better quality of life with neuropsychological improvement on
} HAART

\author{
Thomas D Parsons*, Alyssa J Braaten ${ }^{\dagger}$, Colin D Hall ${ }^{\dagger}$ and Kevin R Robertson ${ }^{\dagger}$
}

Address: AIDS Neurological Center, University of North Carolina at Chapel Hill, 3114 Bioinformatics Building, Chapel Hill, NC 27599-7025, USA

Email: Thomas D Parsons* - tparsons@neurology.unc.edu; Alyssa J Braaten - braatena@neurology.unc.edu;

Colin D Hall - hallc@neurology.unc.edu; Kevin R Robertson - kevinr@neurology.unc.edu

* Corresponding author †Equal contributors

Published: 24 February 2006

Health and Quality of Life Outcomes 2006, 4:II doi:10.1 186/1477-7525-4-I I

Received: 04 October 2005

Accepted: 24 February 2006

This article is available from: http://www.hqlo.com/content/4/I/II

(C) 2006 Parsons et al; licensee BioMed Central Ltd.

This is an Open Access article distributed under the terms of the Creative Commons Attribution License (http://creativecommons.org/licenses/by/2.0), which permits unrestricted use, distribution, and reproduction in any medium, provided the original work is properly cited.

\begin{abstract}
Background: Successful highly active antiretroviral therapy (HAART) regimens have resulted in substantial improvements in the systemic health of HIV infected persons and increased survival times. Despite increased systemic health, the prevalence of minor HIV-associated cognitive impairment appears to be rising with increased longevity, and it remains to be seen what functional outcomes will result from these improvements. Cognitive impairment can dramatically impact functional ability and day-to-day productivity. We assessed the relationship of quality of life (QOL) and neuropsychological functioning with successful HAART treatment.
\end{abstract}

Methods: In a prospective longitudinal study, subjects were evaluated before instituting HAART (naive) or before changing HAART regimens because current therapy failed to maintain suppression of plasma viral load (treatment failure). Subjects underwent detailed neuropsychological and neurological examinations, as well as psychological evaluation sensitive to possible confounds. Re-evaluation was performed six months after institution of the new HAART regimen and/or if plasma viral load indicated treatment failure. At each evaluation, subjects underwent ultrasensitive HIV RNA quantitative evaluation in both plasma and cerebrospinal fluid.

Results: HAART successes performed better than failures on measures exploring speed of mental processing $(p<.02)$. HAART failure was significantly associated with increased self-reports of physical health complaints $(p<.0 \mathrm{I})$ and substance abuse $(p<.0 \mathrm{I})$. An interesting trend emerged, in which HAART failures endorsed greater levels of psychological and cognitive complaints $(p=$ .06). Analysis between neuropsychological measures and QOL scores revealed significant correlation between QOL Total and processing speed $(p<.05)$, as well as flexibility $(p<.05)$.

Conclusion: Our study investigated the relationship between HIV-associated neurocognitive impairment and quality of life. HAART failures experienced slower psychomotor processing, and had increased self-reports of physical health complaints and substance abuse. Contrariwise, HAART successes experienced improved mental processing, demonstrating the impact of successful treatment on functioning. With increasing life expectancy for those who are HIV seropositive, it is important to measure cognitive functioning in relation to the actual QOL these individuals report. The study results have implications for the optimal management of HIV-infected persons. Specific support or intervention may be beneficial for those who have failed HAART in order to decrease substance abuse and increase overall physical health. 


\section{Background}

Cognitive impairments are known to be associated with human immunodeficiency virus (HIV) infection. In HIV1 -associated minor cognitive/motor disorders patient profiles are characterized by impaired motor speed and working memory [1]. Contrariwise, attention, visuoconstructive abilities, and memory are relatively unimpaired [2-4]. In HIV-1-associated dementia, behavioral changes, attention and executive dysfunction, psychomotor slowing, and memory impairment mark patient profiles [5]. Although highly active antiretroviral therapy (HAART) has reduced the incidence of HIV dementia, HIV-associated cognitive impairment continues to be a major clinical problem among individuals with advanced infection [6]. Given the large number of potential pathways by which HIV-1 enters brain tissue, persists, and is activated over time, there is a significant possibility that HIV-1-associated cognitive-motor disorders may yet increase as a consequence of increasing resistance to HAART regimens [7]. Moreover, individuals with HIV-1 infection may experience various neurobehavioral changes. For example, the debilitating nature of the HIV disease course has been found to be associated with increased depression and anxiety, as well as poor quality of life [8].

Successful HAART regimens have resulted in substantial improvements in the systemic health of patients with HIV infection and increased survival times. However, with the increased longevity of HIV patients, the prevalence of minor HIV-associated cognitive impairment appears to be rising among HAART successes. HAART has been shown to successfully restore immune function and reduce the effects of opportunistic infection. This restoration of immune function results in a marked improvement of HIV-associated diseases and in the reduction of AIDSrelated mortality [9]. However, although HAART improves physical health, the treatment's effects on neurocognitive and affective symptoms are unclear. Some studies have shown significant improvement in cognitive functioning $[10,11]$, while others have shown that some patients continue to exhibit neurocognitive impairment even after extended periods of HAART $[12,13]$. In one study HIV-associated neurocognitive impairment was found to be present in nearly one-third of patients on HAART [14].

In addition to neurocognitive deficits, patients afflicted with HIV often exhibit affective disorders such as depression and anxiety. In fact, lower quality of life scores have been found to be associated with a diagnosis of HIV and with disease-related symptoms [8,15-17]. Neurocognitive and affective symptoms appear to be directly related, as patients exhibiting deficits on neuropsychological testing also report increased levels of depression and/or anxiety on self-report measures. This relationship is likely explicated by the fact that cognitively impaired patients are less likely to employ effective strategies to manage stressors and in turn to alleviate symptoms of depression and anxiety [18]. HAART seems to lessen the affective symptoms associated with HIV infection $[19,20]$, likely due to the reduction of physical symptoms associated with the disorder.

Quality of life in HIV infection has been shown to be directly associated with disease stage, disease symptoms, and cognitive function [14]. Specifically, impairment in cognitive abilities including fine motor functions, memory, mental flexibility, concentration, speed of mental processing, visuospatial abilities, and constructional abilities correlate with reduced quality of life [18]. This finding reinforces the fact that patient's perceptions of their quality of life is related to their ability to function in society and their ability to succeed in activities of daily living [18]. Further, quality of life has been found to improve with antiretroviral therapy $[21,22]$. Significant improvements in the quality of life of symptomatic HIV subjects have been noted on quality of life measures following antiretroviral therapy [23]. Thus, a combination of cognitive functioning, affective disturbance, and physical symptoms need to be considered when assessing patient's quality of life and the overall functional outcome of HAART treatment.

While the effects of HAART have resulted in substantial improvements in the systemic health of patients with HIV infection, it remains to be seen what functional outcomes will result from these improvements. Impairment in cognition can have dramatic impacts on the ability to function on a day-to-day basis, and to be productive. Initial studies have demonstrated that neurocognitive improvement occurs in most patients on HAART therapy. In this study, we assess the relationship of quality of life and neuropsychological functioning with successful HAART treatment.

\section{Methods}

The University of North Carolina Institutional Review Board approved the study, and all participants gave informed consent for participation. Participants were enrolled in the study under the following conditions: 1) if they were about to start HAART; or 2) if, in the opinion of their infectious disease clinician, their current HAART had failed and they required a different HAART regimen. There was no requirement for (or stratification by) presence of neurologic disease at study entry. Prior to starting or changing an antiretroviral regimen, a baseline evaluation was conducted. Participants were reevaluated after 6 months of stable HAART or when, in the opinion of the treating infectious disease physician, the new regimen 
Table I: Demographic, virologic, and immunologic variables

\begin{tabular}{lcc}
\hline Variable & Baseline & During HAART \\
\hline Age $(\mathrm{y})$ & $41.00 \pm 7.77$ & $42.52 \pm 7.58$ \\
Education $(\mathrm{y})$ & $12.00 \pm 2.19$ & $12.00 \pm 2.15$ \\
Plasma HIV level (log copies $/ \mathrm{mL})$ & $4.87 \pm 1.41$ & $3.04 \pm 1.84$ \\
CSF HIV level (log copies $/ \mathrm{mL})$ & $3.04 \pm 1.47$ & $1.41 \pm 1.23$ \\
CD4+ cell count $(/ \mathrm{mm} 3)$ & $203 \pm 183.47$ & $290 \pm 242.89$ \\
\hline
\end{tabular}

Note: For all analyses $N=59$. Data are mean $\pm S D$; CSF $=$ cerebrospinal fluid

failed. A neurologist conducted a quantified previously validated examination particularly sensitive to the changes found in HIV disease at each evaluation. At each evaluation, a neuropsychologist conducted detailed psychological and neuropsychological evaluations that have also been validated as sensitive to the neurocognitive changes found in HIV disease. At each evaluation, subjects also underwent ultrasensitive HIV RNA quantitative evaluation of both plasma and cerebrospinal fluid.

\section{HIV RNA Load}

Viral load assessment was performed through plasma and cerebrospinal fluid measurements. Within eight hours of the neurologic evaluation, specimens for viral load and immune functioning were obtained. Blood and cerebrospinal fluid samples were obtained within 3 hours of each other. Cerebrospinal fluid samples were centrifuged to remove cells. The Roche Ultrasensitive assay was used to measure Quantitative HIV-1 RNA load. Prior to viral load analysis, neurologic and neuropsychological evaluations were completed in a blinded fashion.

\section{Neurologic examination}

The Price and Sidtis [24] AIDS Clinical Trials Group full neurologic evaluation was used. The neurologic evaluation includes a global assessment of HAD (AIDS dementia complex stage), which varies from equivocal $(0.5)$ to severe (3.0) dementia. To increase the sensitivity of the instrument and to provide domains of functioning, a quantitative scoring procedure for the neurologic evaluation was implemented, which provides a weighted scoring approach to the items of the neurologic examination and yields an overall neurologic total score as well as scores for cognitive, frontal, pyramidal, extrapyramidal, cranial nerve, cerebellar, spinal, autonomic, sensory, and peripheral domains.

\section{Neuropsychological evaluation}

The neuropsychological evaluation included assessment of the following domains: attention/concentration (2 and 7 test, PASAT), speed of processing (computerized simple and choice reaction time tasks, digit symbol, trailmaking A, stroop word), executive functioning (trailmaking B, stroop colorword, COWA), visuospatial (Rey complex figure copy), verbal memory (RAVLT), figural memory (Rey complex figure immediate, delay), gross motor (timed gait), fine motor (grooved pegboard, finger tapping), and language (WAIS-R Vocabulary).

\section{Quality of Life}

The Neurological Quality of Life questionnaire (NeuroQOL) is a self report instrument which assesses eleven domains: Security, Food, Housing, Financial, Productivity, Social support, Relationships, Psychological health, Physical health, Substance abuse, and Cognitive/Neurological problems. The NeuroQOL questionnaire contains 114 items answered in Likert format. The items are summed for a total score, with higher scores reflecting better quality of life $[25,26]$.

\section{Memorial Sloan Kettering dementia staging}

Subsequent to each visit, the Memorial Sloan Kettering dementia scale was determined for each participant at a consensus conference, utilizing the neurologic and neuropsychological evaluations, the psychiatric interview, and the quality of life scale. The Memorial Sloan Kettering dementia scale is as follows: normal, 0 ; equivocal (deficits

Table 2: Comparison of success and failure groups on neuropsychological tests

\begin{tabular}{|c|c|c|c|c|}
\hline & Failure Mean & Success Mean & t-value & $\mathbf{p}$ \\
\hline Attention & -0.14 & -0.22 & 0.33 & 0.74 \\
\hline Speed & -0.78 & 0.09 & -2.46 & 0.02 \\
\hline Flexibility & -0.59 & -0.61 & 0.07 & 0.95 \\
\hline Visual & -0.52 & -0.40 & -0.33 & 0.74 \\
\hline Verbal & -0.52 & -0.63 & 0.45 & 0.65 \\
\hline Figural & -0.23 & -0.39 & 0.78 & 0.44 \\
\hline Fine Motor & -0.54 & -0.08 & -1.14 & 0.26 \\
\hline Gross Motor & -0.24 & 0.12 & -0.46 & 0.65 \\
\hline Language & -0.21 & 0.08 & -1.22 & 0.23 \\
\hline $\begin{array}{l}\text { Neuropsychology Total Z- } \\
\text { score }\end{array}$ & -0.52 & -0.21 & -1.48 & 0.14 \\
\hline
\end{tabular}

Note: For all analyses $\mathrm{N}=59$. 
Table 3: Comparison of success and failure groups on NeuroQOL

\begin{tabular}{|c|c|c|c|c|}
\hline & Failure Mean & Success Mean & t-value & $\mathbf{p}$ \\
\hline Food & 4.63 & 2.78 & 1.20 & 0.23 \\
\hline Housing & 9.44 & 4.56 & 1.66 & 0.10 \\
\hline Financial & 3.91 & 0.84 & 1.28 & 0.20 \\
\hline Product & 5.91 & 4.06 & 0.62 & 0.54 \\
\hline Social & 6.17 & 3.47 & 0.98 & 0.33 \\
\hline Relation & 7.80 & 6.88 & 0.27 & 0.79 \\
\hline Psych & 26.78 & 9.38 & 1.85 & 0.07 \\
\hline Physical & 18.02 & 2.50 & 2.64 & 0.01 \\
\hline Substance & 7.67 & 0.06 & 2.80 & 0.01 \\
\hline Cognitive & 12.19 & 3.59 & 1.88 & 0.06 \\
\hline NeuroQOL Total & 106.98 & 41.53 & 1.82 & 0.07 \\
\hline
\end{tabular}

Note: For all analyses $N=59$. NeuroQOL Total is the total score for the Quality of Life measure.

Mean $=82.63$. Standard deviation $=163.47$

that do not reach the stage of clear dementia), 0.5 ; and dementia, 1-3 (depending on severity) [24].

\section{HAART treatment success and failure}

We defined success and failure on HAART by both virological and immunological changes. We defined virological success as a decrease in plasma HIV RNA by 1.5 log cop$\mathrm{ies} / \mathrm{ml}$ and to less than $2.5 \mathrm{log}$ copies/ml. Virological failures were defined as a decrease of less then $1.5 \log$ copies/ $\mathrm{ml}$ or a failure to reduce HIV RNA below 2.5 log copies/ $\mathrm{ml}$. We defined immunological success as an increase in $\mathrm{CD} 4+$ cell count. Immunological failure was defined as stable or decreased absolute CD4+ cell count.

\section{Data analysis}

First, HAART treatment and results on the neuropsychological battery were compared between groups (HAART success group and HAART failure group) by using t tests and an alpha level of 0.05. Next, HAART treatment and results on the NeuroQol were compared between groups (HAART success group and HAART failure group) by using t tests and an alpha level of 0.05 . Pearson productmoment correlation was used to analyze the relationship between performance on the neurocognitive tasks and NeuroQol domains.

\section{Results}

Eighty-six subjects were evaluated at baseline before treatment with HAART or after failing one treatment regimen and before instituting a different HAART regimen. Fifty nine of those then underwent six-month follow-up on stable HAART. As an ongoing study with continuous enrollment, seven of these participants did not have opportunity to attend their 6-month followup, as the data base was cut prior to their 6-month follow up. The dropout characteristics of the remaining participants include: five participants refused lumbar puncture, five had illicit drug problems, 2 never started HAART, 2 went to prison, 2 had other health related problems, and 2 moved out of the area. Of those with follow-up $(\mathrm{N}=59)$, the median age was 42.52 years $(\mathrm{SD}=7.58)$ and a median educational level of 12 years ( $S D=2.15$ years). The median $\mathrm{CD} 4+$ cell count was $290(\mathrm{SD}=242.89)$, and the median plasma HIV RNA was 3.04 (SD = 1.84). Demographic, virologic, and immunologic variables are listed on Table 1.

Forty $(68 \%)$ subjects were male and 19 were female $(32 \%)$. Forty-four $(75 \%)$ were black, $13(22 \%)$ white, 1 was Asian and 1 was Native American. Forty (68\%) had AIDS by CDC criteria, 7 (12\%) were symptomatic and 12 $(20 \%)$ were asymptomatic.

A quantitative scoring procedure was utilized for the neurological exam, and summary z-scores were calculated for the neuropsychological battery.

Participants with successful HAART treatment performed better than failure patients on measures exploring speed of mental processing $(\mathrm{t}=-2.46 ; \mathrm{p}<.02)$. For complete results comparing Success and Failure groups on neuropsychological measures, see Table 2 . The presence of HAART failure was significantly associated with increased self-reports of physical health complaints $(\mathrm{t}=2.64$; $\mathrm{p}<$ $.04)$. Further, there was an interesting trend, in which the HAART failure group endorsed greater levels of psychological $(\mathrm{t}=1.85 ; \mathrm{p}=.07)$ and cognitive complaints $(\mathrm{t}=$ $1.88 ; \mathrm{p}=.06)$. For complete results comparing Success and Failure groups on quality of life measures, see Table 3. Analysis between neuropsychological measures and quality of life scores revealed significant correlation between NeuroQOL Total and processing speed $(r=-.27$; $\mathrm{p}<.01)$, as well as flexibility $(\mathrm{r}=-.24 ; \mathrm{p}<.03)$. For complete correlational results see Table 4 . 
Table 4: Correlations between NeuroQOL total and neuropsychological measures

\begin{tabular}{lcccc}
\hline & Mean & Std.Dv. & $\mathbf{r ( X , Y )}$ & $\mathbf{P}$ \\
\hline Attention & -0.17 & 1.11 & 0.01 & $\mathrm{Ns}$ \\
Speed & -0.45 & 1.64 & -0.27 & 0.01 \\
Flexibility & -0.60 & 1.64 & -0.24 & 0.03 \\
Visual & -0.48 & 1.69 & 0.03 & $\mathrm{Ns}$ \\
Verbal & -0.56 & 1.08 & 0.23 & $\mathrm{Ns}$ \\
Figural & -0.29 & 0.89 & 0.13 & $\mathrm{Ns}$ \\
Fine Motor & -0.37 & 1.79 & 0.08 & $\mathrm{Ns}$ \\
Gross Motor & -0.11 & 3.48 & 0.34 & $\mathrm{Ns}$ \\
Language & -0.10 & 1.09 & 0.74 & $\mathrm{Ns}$ \\
\hline
\end{tabular}

Note: For all analyses $N=59$. NeuroQOL Total is the total score for the Quality of Life measure.

Mean $=82.63$. Standard deviation $=163.47$

\section{Discussion}

Our study investigated the relationship between HIVassociated neurocognitive impairment and quality of life. Our findings revealed that subjects who failed HAART experienced slower psychomotor processing, and had increased self-reports of physical health complaints and substance abuse. On the other hand, those with successful HAART experienced improved mental processing, demonstrating the impact of successful treatment on functioning.

Restoration of immune function results in a marked improvement of HIV-associated diseases and in the reduction of AIDS-related mortality [9]. With increasing life expectancy for those who are HIV seropositive, it is important to measure cognitive functioning in relation to the actual quality of life these individuals report. Our results revealed that participants with successful HAART treatment performed better than failure patients on measures exploring speed of mental processing, which reflects the current literature [27]. We also found significant correlations between total quality of life and processing speed, as well as flexibility.

The presence of HAART failure was significantly associated with increased self-reports of physical health complaints. These findings reflect current literature, in which lower quality of life scores have been found to be associated with a diagnosis of HIV and with disease-related symptoms [8,15-17]. Further, there was an interesting trend, in which the HAART failure group endorsed greater levels of psychological and cognitive complaints. These findings are consistent with findings that neurocognitive and affective symptoms appear to be directly related, as patients exhibiting deficits on neuropsychological testing also report decreased quality of life. This relationship is likely explicated by the fact that cognitively impaired patients are less likely to employ effective strategies to manage stressors and in turn to alleviate symptoms of depression and anxiety [18].

Quality of life in HIV infection has been shown to be directly associated with disease stage, disease symptoms, and cognitive function $[14,28]$. Specifically, impairment in cognitive abilities including fine motor functions, memory, mental flexibility, concentration, speed of mental processing, visuospatial abilities, and constructional abilities correlate with reduced health-related quality of life [18]. Our findings reinforce the fact that patient's perceptions of their quality of life is related to their ability to function in society and their ability to succeed in activities of daily living [18]. Thus, a combination of cognitive functioning, affective disturbance, and physical symptoms need to be considered when assessing patient's quality of life and the overall functional outcome of HAART treatment.

The study results have implications for the optimal management of HIV-infected patients' neurocognitive impairment. Our findings support continued investigation of the presence of neurocognitive impairment in the HAART era. The association we found with poor quality of life scores further emphasizes this need. Given these findings, specific support or intervention may be beneficial for those who have failed HAART in order to decrease substance abuse and increase overall physical health. As a subjective evaluation of persons with HIV related illness, quality of life provides information relevant to patient care, and health promoting activities. Specific support or intervention may be beneficial for those who have failed HAART in order to increase a person's ability to achieve and maintain a level of overall functioning necessary to decrease substance abuse and increase overall physical health. The identifying of factors that diminish quality of life in HIV cases is an important step towards improving quality of life in this population. Further, it allows for screening of these factors, and in situations where these factors are present, it aides the clinician in planning and implementing interventions.

Future studies should look at the relations among quality of life, adherence, substance abuse, neurocognitive scores, and virological and immunological outcome. Adherence is a critical component for therapeutic success in HIV infection and has been shown to be a major determinant of biological outcome measures in HIV. Substance abuse has been associated with decreased adherence in several studies [29,30]. Divergent findings have resulted from studies investigating adherence and quality of life [31-33]. The relationship between quality of life, adherence, and neurocognitive sequelae has not been well studied. Hence, future studies should look at the interrelations among quality of life, adherence, substance abuse, neuro- 
cognitive scores, and virological and immunological outcome.

\section{Conclusion}

In summary, our assessment of quality of life and neuropsychological functioning with HAART treatment revealed that HAART success was significantly related to processing speed. HAART failure was significantly associated with increased physical health complaints, substance abuse, and a trend toward increased psychological and cognitive complaints. Significant correlations were found between quality of life and processing speed, as well as flexibility. Future studies should include risk and/or severity factors and look at the relationship between quality of life, adherence, and neurocognitive sequelae.

\section{Authors' contributions}

TDP, KRR and CDH planned the study and collected the data. KRR identified the patient cohort and collected the data. TDP performed the statistical analysis and drafted the manuscript together with KRR, CDH, and AJB (TDP, KRR, CDH, and AJB contributed equally to this study). All authors read and approved the final manuscript.

\section{Acknowledgements}

This work was supported by the following NIH grants: ROI MH62690, Al25868, RR00046, 9P30 Al 504I0.

\section{References}

I. Saykin AJ, Janssen RS, Sprehn GC, Kaplan JE, Spira TJ, O'Connor B: Longitudinal evaluation of neuropsychological function in homosexual men with HIV infection: I 8-month follow-up. J Neuropsychiatry Clin Neurosci I99I, 3(3):286-298.

2. Dunbar N, Perdices M, Grunseit A, Cooper DA: Changes in neuropsychological performance of AIDS-related complex patients who progress to AIDS. Aids 1992, 6(7):69|-700.

3. Selnes OA, Galai N, Bacellar H, Miller EN, Becker JT, Wesch J, Van Gorp W, McArthur JC: Cognitive performance after progression to AIDS: a longitudinal study from the Multicenter AIDS Cohort Study. Neurology 1995, 45(2):267-275.

4. Stout JC, Salmon DP, Butters N, Taylor M, Peavy G, Heindel WC, Delis DC, Ryan L, Atkinson JH, Chandler JL, et al.: Decline in working memory associated with HIV infection. HNRC Group. Psychol Med 1995, 25(6): I22I-I 232.

5. Bornstein RA, Nasrallah HA, Para MF, Whitacre CC, Rosenberger P, Fass RJ: Neuropsychological performance in symptomatic and asymptomatic HIV infection. Aids 1993, 7(4):519-524.

6. Goodkin K, Wilkie FL, Concha M, Hinkin CH, Symes S, Baldewicz TT, Asthana D, Fujimura RK, Lee D, van Zuilen MH, Khamis I, Shapshak $P$, Eisdorfer $C$ : Aging and neuro-AIDS conditions and the changing spectrum of HIV-I-associated morbidity and mortality. J Clin Epidemiol 200I, 54 SuppI I:S35-43.

7. Major EO, Rausch D, Marra C, Clifford D: HIV-associated dementia. Science 2000, 288(5465):440-442.

8. Bing EG, Hays RD, Jacobson LP, Chen B, Gange SJ, Kass NE, Chmiel JS, Zucconi SL: Health-related quality of life among people with HIV disease: results from the Multicenter AIDS Cohort Study. Qual Life Res 2000, 9(I):55-63.

9. Paredes R, Mocroft A, Kirk O, Lazzarin A, Barton SE, van Lunzen J, Katzenstein TL, Antunes F, Lundgren JD, Clotet B: Predictors of virological success and ensuing failure in HIV-positive patients starting highly active antiretroviral therapy in Europe: results from the EuroSIDA study. Arch Intern Med 2000, I60(8): II $123-1132$.

10. Robertson KR, Robertson WT, Ford S, Watson D, Fiscus S, Harp AG, Hall CD: Highly active antiretroviral therapy improves neuro- cognitive functioning. I Acquir Immune Defic Syndr 2004, 36(I):562-566.

II. Tozzi V, Balestra P, Galgani S, Narciso P, Ferri F, Sebastiani G, D'Amato C, Affricano C, Pigorini F, Pau FM, De Felici A, Benedetto $A$ : Positive and sustained effects of highly active antiretroviral therapy on HIV-I-associated neurocognitive impairment. Aids 1999, 13(14): 1889-1897.

12. Starace F, Bartoli L, Aloisi MS, Antinori A, Narciso P, Ippolito G, Ravasio L, Moioli MC, Vangi D, Gennero L, Coronado OV, Giacometti A, Nappa S, Perulli ML, Montesarchio V, La Gala A, Ricci F, Cristiano L, De Marco M, Izzo C, Pezzotti P, D'Arminio Monforte A: Cognitive and affective disorders associated to HIV infection in the HAART era: findings from the NeurolCONA study. Cognitive impairment and depression in HIVIAIDS. The NeurolCONA study. Acta Psychiatr Scand 2002, I06(I):20-26.

13. Tozzi V, Balestra P, Galgani S, Narciso P, Sampaolesi A, Antinori A, Giulianelli M, Serraino D, Ippolito G: Changes in neurocognitive performance in a cohort of patients treated with HAART for 3 years. J Acquir Immune Defic Syndr 200I, 28(I): 19-27.

14. Tozzi V, Balestra P, Murri R, Galgani S, Bellagamba R, Narciso P, Antinori A, Giulianelli M, Tosi G, Fantoni M, Sampaolesi A, Noto P, Ippolito G, Wu AW: Neurocognitive impairment influences quality of life in HIV-infected patients receiving HAART. Int J STD AIDS 2004, I 5(4):254-259.

15. Hays RD, Cunningham WE, Sherbourne CD, Wilson IB, Wu AW, Cleary PD, McCaffrey DF, Fleishman JA, Crystal S, Collins R, Eggan F, Shapiro MF, Bozzette SA: Health-related quality of life in patients with human immunodeficiency virus infection in the United States: results from the HIV Cost and Services Utilization Study. Am J Med 2000, 108(9):71 4-722.

16. Lorenz KA, Shapiro MF, Asch SM, Bozzette SA, Hays RD: Associations of symptoms and health-related quality of life: findings from a national study of persons with HIV infection. Ann Intern Med 200I, I34(9 Pt 2):854-860.

17. Nieuwkerk PT, Gisolf EH, Colebunders R, Wu AW, Danner SA, Sprangers MA: Quality of life in asymptomatic- and symptomatic HIV infected patients in a trial of ritonavir/saquinavir therapy. The Prometheus Study Group. Aids 2000, 14(2): $181-187$.

18. Tozzi V, Balestra P, Galgani S, Murri R, Bellagamba R, Narciso P, Antinori A, Giulianelli M, Tosi G, Costa M, Sampaolesi A, Fantoni M, Noto $P$, Ippolito G, Wu AW: Neurocognitive performance and quality of life in patients with HIV infection. AIDS Res Hum Retroviruses 2003, 19(8):643-652.

19. Judd FK, Cockram AM, Komiti A, Mijch AM, Hoy J, Bell R: Depressive symptoms reduced in individuals with HIVIAIDS treated with highly active antiretroviral therapy: a longitudinal study. Aust N ZJ Psychiatry 2000, 34(6): 1015-1021.

20. Low-Beer S, Chan K, Wood E, Yip B, Montaner JS, O'Shaughnessy MV, Hogg RS: Health related quality of life among persons with HIV after the use of protease inhibitors. Qual Life Res 2000, 9(8):94I-949.

21. Fumaz CR, Tuldra A, Ferrer MJ, Paredes R, Bonjoch A, Jou T, Negredo E, Romeu J, Sirera G, Tural C, Clotet B: Quality of life, emotional status, and adherence of HIV-I-infected patients treated with efavirenz versus protease inhibitor-containing regimens. J Acquir Immune Defic Syndr 2002, 29(3):244-253.

22. Nieuwkerk PT, Gisolf EH, Reijers MH, Lange JM, Danner SA, Sprangers MA: Long-term quality of life outcomes in three antiretroviral treatment strategies for HIV-I infection. Aids 200I, I5(I5): I985-1991.

23. Revicki DA, Moyle G, Stellbrink HJ, Barker C: Quality of life outcomes of combination zalcitabine-zidovudine, saquinavirzidovudine, and saquinavir-zalcitabine-zidovudine therapy for HIV-infected adults with CD4 cell counts between 50 and 350 per cubic millimeter. PISCES (SV I4604) Study Group. Aids 1999, 13(7):851-858.

24. Price RW, Sidtis J]: Evaluation of the AIDS dementia complex in clinical trials. J Acquir Immune Defic Syndr 1990, 3 Suppl 2:S5I-60.

25. Robertson KRWSRWTHCD: An instrument to assess Quality of Life: Validity. Neurosciences of HIV infection: Basic and Clinical Frontiers Clinical Neuropathology: An International Journal 1993, I2(Supp I):S33.

26. Robertson KRWSRWTHCD: An instrument to assess Quality of Life: Reliability. Neurosciences of HIV infection: Basic and Clinical 
Frontiers Clinical Neuropathology: An International Journal 1993, I2(Supp I):S33.

27. Ferrando SJ, Rabkin JG, van Gorp W, Lin SH, McElhiney M: Longitudinal improvement in psychomotor processing speed is associated with potent combination antiretroviral therapy in HIV-I infection. J Neuropsychiatry Clin Neurosci 2003, I 5(2):208-2I 4.

28. Tsevat J, Solzan JG, Kuntz KM, Ragland J, Currier JS, Sell RL, Weinstein MC: Health values of patients infected with human immunodeficiency virus. Relationship to mental health and physical functioning. Med Care 1996, 34(I):44-57.

29. Chesney MA, Ickovics JR, Chambers DB, Gifford AL, Neidig J, Zwickl $B$, Wu AW: Self-reported adherence to antiretroviral medications among participants in HIV clinical trials: the AACTG adherence instruments. Patient Care Committee \& Adherence Working Group of the Outcomes Committee of the Adult AIDS Clinical Trials Group (AACTG). AIDS Care 2000, I 2(3):255-266.

30. Duran S, Spire B, Raffi F, Walter V, Bouhour D, Journot V, Cailleton $V$, Leport C, Moatti JP: Self-reported symptoms after initiation of a protease inhibitor in HIV-infected patients and their impact on adherence to HAART. HIV Clin Trials 200I, 2(I):38-45.

31. Holzemer WL, Corless IB, Nokes KM, Turner JG, Brown MA, PowellCope GM, Inouye J, Henry SB, Nicholas PK, Portillo CJ: Predictors of self-reported adherence in persons living with HIV disease. AIDS Patient Care STDS 1999, I3(3): 185-197.

32. Singh N, Berman SM, Swindells S, Justis JC, Mohr JA, Squier C, Wagener MM: Adherence of human immunodeficiency virusinfected patients to antiretroviral therapy. Clin Infect Dis 1999, 29(4):824-830.

33. Wilson TE, Barron Y, Cohen M, Richardson J, Greenblatt R, Sacks HS, Young M: Adherence to antiretroviral therapy and its association with sexual behavior in a national sample of women with human immunodeficiency virus. Clin Infect Dis 2002, 34(4):529-534.

\section{Publish with Bio Med Central and every scientist can read your work free of charge}

"BioMed Central will be the most significant development for disseminating the results of biomedical research in our lifetime. "

Sir Paul Nurse, Cancer Research UK

Your research papers will be:

- available free of charge to the entire biomedical community

- peer reviewed and published immediately upon acceptance

- cited in PubMed and archived on PubMed Central

- yours - you keep the copyright

Submit your manuscript here:

http://www.biomedcentral.com/info/publishing_adv.asp 